\title{
Type III Interferons IL-28 and IL-29: Novel Interferon Family Members with Therapeutic Potential in Cancer Therapy
}

\author{
Hitomi Fujie and Muneo Numasaki \\ Department of Nutrition Physiology, Pharmaceutical Sciences, \\ Josai University, Sakado, Saitama, \\ Japan
}

\section{Introduction}

Type I interferons (IFNs), namely IFN- $\alpha / \beta$, were originally discovered due to its powerful antiviral activity [1,2]. Type I IFNs were later shown to have pleiotropic biological activities, including modulation of innate and acquired immune responses, cell growth and apoptosis, in addition to their well-known ability to inhibit virus replication [3]. Type I IFN forms a vast multigenic family [4]. The human genome carries the intronless genes encoding 13 functionally and structurally related IFN- $\alpha$ subtypes and a single IFN- $\beta$ molecule [5]. In

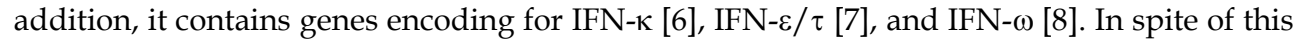
remarkable variability, all type I IFN subtypes appear to bind the same heterodimeric receptor [4].

Type I IFNs have been used for the clinical treatment of several malignancies including renal cell carcinoma, melanoma, Kaposi's sarcoma, hairy cell leukemia and chronic myeloid leukemia. For a long time, it was thought that the direct actions on tumor cells were the major mechanisms involved in the antitumor responses observed in type I IFN-treated patients [9]. Actually, type I IFNs are able to directly inhibit the proliferation of tumor cells in vitro and in vivo, and exert other direct effects on tumor cells including induction of apoptosis and enhancement of major histocompatibility complex (MHC) class I expression, which can enhance immune recognition [10]. In addition to the direct effects on tumor cells, type I IFNs exert multiple biological effects on host immune cells, especially $\mathrm{T}$ cells and dendritic cells, that can play a central role in the overall antitumor responses [11].

Type III IFNs, also termed IFN- $\lambda s$, were discovered independently by 2 different research groups in 2003 [12, 13]. The type III IFN family consists of IFN- $\lambda 1$, IFN- $\lambda 2$ and IFN- $\lambda 3$, also referred to as interleukin (IL)-29, IL-28A and IL-28B, respectively. On the basis of sequence and protein structure, type III IFNs are more similar to the IL-10 family of cytokines, but the deciding factor that led to the classification of IL-29, IL-28A and IL-28B as IFNs was their antiviral function and induction of IFN-stimulated genes (ISGs) [12,13]. In humans, among these molecules, only IL-29 is glycosylated $[12,13]$. In the mouse system, the IL-29 gene is a pseudogene. The IL-28A and IL-28B genes encode glycosylated protein [14]. 
Type III IFN expression has been shown to depend on the same triggers (viral infection or Toll-like receptor (TLR) ligands) $[12,13,15,16,17,18,19,20]$ and signal transduction pathway as those inducing type I IFN expression. Type I IFNs and type III IFNs bind distinct heterodimeric receptors $[12,13]$. The type I IFN receptor is made of the ubiquitously expressed IFN- $\alpha$ R $\alpha$ and IFN- $\alpha$ Rß subunits [21]. The type III IFN receptor is comprised of the IL-10Rß subunit which is widely expressed and shared by other IL-10-related cytokines, and of the IL-28R subunit, which is specific to type III IFN and responsible for signal transduction $[12,13,21]$. While the receptor subunits of type III IFNs display no detectable homology to those of type I IFNs, they elicit strikingly similar intracellular responses, mostly through the activation of several latent transcriptional factors of the signal transducer and activator of transcription (STAT) family including STAT1, STAT2, STAT3, STAT4 and STAT5 [12, 22, 23]. In particular, type III IFN receptor engagement leads to the phosphorylation of STAT1 and STAT2 and the formation of the interferon-stimulated gene factor 3 (ISGF3) transcription complex, which is composed of STAT1, STAT2 and IFN regulatory factor (IRF) 9/p48 [12], and to the induction of myxovirus resistance A (MxA) and oligoadenylate synthetase (OAS)1, which mediate the antiviral effects of type I IFN [12, 24]. Initially, type I IFNs and type III IFNs were also considered to lead to activation of the mitogen-activated protein (MAP) kinases c-Jun N-terminal kinase (JNK) and p38, but not extracellular signal-regulated kinase (ERK) [24]. Accordingly, type III IFNs have been shown to elicit biological activities including antiviral, antiproliferative and immunomodulatory properties, similar to those of type I IFNs. Therefore, despite the structural difference and the utilization of a distinct receptor system, type III IFN seems to be functionally related to type I IFN.

In the first half of this chapter, we will summarize the current knowledge on the novel IFN family member type III IFN and, in the latter half, we will review studies from several laboratories, including our group, displaying direct and indirect antitumor activities of type III IFNs with the usage of various histological types of human tumor cell lines and xenogeneic models of human esophageal carcinoma and non-small cell lung cancer (NSCLC), and genetically modified tumor cells in murine tumor models.

\section{Type III IFN-encoding genes and regulation of production}

In 2003, two research groups independently reported the identification of a small family of interferon like cytokines through computational analysis of the human genome sequence database $[12,13]$. This novel family of interferon consists of three family members, which were referred to alternatively as IFN- $\lambda 1$, IFN- $\lambda 2$ and IFN- $\lambda 3$, or IL-29, IL-28A, and IL-28B, respectively. The genes encoding human IL-28A, IL-28B and IL-29 are located on the same genomic contig, which is from chromosomal region 19q13.13 [12, 13]. This chromosomal location differs from the type I and type II interferon families clustered on chromosome 9 and chromosome 12, respectively. The genes encoding type III IFNs are composed of multiple exons, 5 for IL-29, and 6 for IL-28A and IL-28B, resembling the structural organization of genes encoding IL-10-related cytokines [12, 13]. This is in clear contrast to type I IFNs, which are encoded within a single exon. At amino acid level, IL-28A has an 81$96 \%$ identity to IL-28B and IL-29, $11-13 \%$ identity to IL-10 and $15-19 \%$ identity to IFN- $\gamma$ and IL-22 $[12,13]$. 
Mouse type III interferon-encoding genes were mapped to chromosome 7A3. This region has a similar organization as the human type III interferon locus [14]. Two genes colinear with the human IL-28A and IL-28B genes are intact and are predicted to encode functional proteins, which are designated mouse IL-28A and IL-28B in accordance with the corresponding human genes [14]. Mouse IL-28A and IL-28B have higher sequence identity to human IL-28A and IL-28B than to IL-29 [14]. In contrast to the IL-28A and IL-28B genes, the mouse IL-29 gene has lost the entire exon 2 and acquired the stop codon within exon 1 , resulting in a pseudogene in all murine strains studied [14]. Both mouse IL-28A and IL-28B possess a site for N-linked glycosylation (Asn ${ }^{105-M e t-T h r ~ i n ~ I L-28 A ~ a n d ~ A s n ~}{ }^{107-A s p-S e r ~ i n ~}$ IL-28B) [14].

Like type I IFNs, type III IFN mRNAs expression was detected at low levels in human blood, brain, lung, ovary, pancreas, pituitary, placenta, prostate, and testis by RT-PCR analysis [25]. Furthermore, there have been many reports that infection of encephalomyocarditis virus (EMCV) [13], Sindbis virus [25], Dengue virus [12], vesicular stomatitis virus (VSV) [10], mengo virus [23], cytomegalo virus (CMV) [24], and Sendai virus [27, 28, 29] leads to transcriptional activation of IL-28A, IL-28B, and IL-29 variously in human peripheral mononuclear cells (PBMC), monocyte-derived dendritic cells (MD-DCs), bronchial epithelial cells and a number of human cell lines. Respiratory syncytial virus induces expression of type III IFNs in monocyte-derived macrophages [30]. Type III IFN mRNAs are co-expressed with IFN- $\alpha$ and IFN- $\beta$ in virally infected cells [10, 11]. Sendai virus infection readily activates the expression of IFN- $\alpha$, IFN- $\beta$, and IFN- $\lambda$ genes, whereas influenza A virus (IAV)induced activation of these genes is mainly dependent on pretreatment of A549 lung alveolar cell carcinoma with IFN- $\alpha$ or tumor necrosis factor (TNF)- $\alpha$ [31]. Although virtually any cell type following viral infection can express type III IFNs, PBMC, MD-DCs and plasmacytoid DCs appear to be the major cellular sources [10, 11, 32]. The antigen presenting cells (APCs) such as DCs and macrophages have been shown to produce and secrete type III IFNs following stimulation with TLR agonists [25, 33]. MD-DCs express low levels of type III IFNs when stimulated with TLR agonists such as lipopolysaccharide (LPS) or polyinosinic:polycytidylic acid [poly(I:C)]. In addition, type III IFNs also have a positive regulatory effect on the expression of type III IFNs. Siren et al. [27] demonstrated this clearly, whereas pretreatment with type III IFNs was shown to enhance the production of type III IFNs by macrophages stimulated with TLR3 and TLR4 agonists. TLR3 ligand poly(I:C) upregulated IFN- $\beta$, IFN- $\lambda$, and TLR3 expression in HUVECs but not in A549 cells. Similarly, IFN- $\alpha$ pretreatment also strongly enhanced poly(I:C)-induced activation of IFN- $\beta$ and IFN- $\lambda$ genes in HUVECs [33]. Although type III IFNs differ genetically and structurally from type I IFNs and use their own specific receptor, the expression of type III IFNs and type I IFNs is regulated in a similar fashion in virus-infected cells exhibiting both early and late phases of interferon induction [15]. However, type III interferon genes are under a more complex regulation than type I interferon genes, since type III interferon genes have a higher number of regulatory elements on their promoters [15]. Type III interferon gene promoters have several putative IFN-stimulated response elements (ISRE) and NF- $\kappa B$ binding sites [30]. The promoter sequences of IL-28A and IL-28B genes are almost identical, whereas the promoter of IL-29 is somewhat different from the IL-28A/B promoters [25]. Namely, NF- $\kappa$ B and multiple IRF family members induce the expression of IL-29 gene [25]. In contrast to IL-29, the IL-28A/B genes are predominantly regulated by an IFN regulatory factor (IRF) family 
member IRF7 [25]. Therefore, the IL-29 gene is mainly regulated by virus-activated IRF3 and IRF7, resembling that of the IFN- $\beta$ gene, whereas IL-28A/B gene expression is mainly controlled by IRF7, resembling those of IFN- $\alpha$ genes [25]. Viral infection serves to activate IRF3, which is expressed broadly and constitutively at high levels in cells, via specific serine phosphorylation events, leading to the synthesis and release of IFNs, predominantly IL-29 and IFN- $B$. In paracrine fashion, these newly released IFNs are free to act on neighboring cells. The binding of IFNs to the respective specific receptor induces expression of another transcriptional activator, IRF7, in a STAT1-dependent manner. When cells expressing other IRF7 are in turn infected with viruses, IRF7 is phosphorylated, and the cells respond by expressing other type III IFN and type I IFN genes, such as IL-29, IL-28A/B, IFN- $\alpha$ and INF-B.

\section{Type III IFN receptor subunit IL-28R}

Type III IFNs act through a cell surface receptor which is composed of the newly identified IL-28R and IL-10Rß with both chains apparently required for full binding affinity $[12,13]$. At the time of its discovery, IL-10Rß has been already known as the second chain of the IL-10 [34], IL-22 [35, 36], or IL-26 receptor [37], formerly known as the class II cytokine receptor (CRF2)-9. IL-28R belongs to members of the class II cytokine receptor family, which are tripartite single-pass transmembrane proteins defined by structural similarities in the extracellular domain including the ligand binding residues [37, 38]. In accordance with the CRF2 characteristics, both transmembrane chains have an extracellular moiety containing two tandem fibronectin III domains, a structural motif in the immunoglobulin fold superfamily, with several amino acid (aa) positions conserved within this receptor family $[38,39]$. Like IL-10, IL-22 and IL-26, the binding of type III IFN to IL-28R induces a conformational change that enables IL-10Rß to interact with the newly formed ligandreceptor complex [40].

The human IL-28R-encoding gene is located on chromosomoe 1p36.11, near the IL22RA1 locus, while the IL-10R-encoding gene is located on 21q22.11, near the IFNAR1, IFNAR2, and IFNGR2 loci $[12,13,41]$. The first exon of the human IL-28R-encoding gene contains 5-UTR and the signal peptide $[12,13]$. The transmembrane moieties are predicted to be encoded by sequences derived from exon 6 of the corresponding genes $[12,13]$. The longer intracellular moiety of IL-28R (predicted 271 aa versus 79 aa in the IL-10Rß) contains three tyrosine residues, which are potential targets for phosphorylation [12, 13]. Dumoutier et al. indicated two tyrosines $\mathrm{Tyr}^{343}$ and $\mathrm{Tyr}^{517}$ of human IL-28R can independently mediate STAT2 activation by type III IFNs [23]. This work also showed that when both tyrosines 343 and 517 were mutated to phenylalanine, antiviral and antiproliferative activities of type III IFNs were completely abolished [23]. The extracellular domains of IL-28R and IL-10Rß contain four putative $\mathrm{N}$-linked glycosylation sites $[12,13]$.

The murine genes encoding IL-28R and IL-10Rß are located on chromosome 4D3 and 16C4, respectively [14]. The mouse IL-28R chain is $\sim 67 \%$ similar to its human counterpart [14]. Although the mouse and human IL-28R sequences are similar, only two of three tyrosine residues of the human receptor intracellular domain are conserved in the mouse orthologue [14]. The mouse receptor contains three additional tyrosine residues [14]. The Try341-based motif of mouse IL-28R (YLERP) shows similarities with that surrounding Tyr ${ }^{343}$ of human 
IL-28R (YLERP). In addition, the COOH-terminal amino acid sequence of mouse IL-28R containing Tyr ${ }^{533}$ (YLVRstop) is similar to the COOH-terminal amino acid sequence of human IL-28R containing Tyr517 (YMARstop). Therefore, both the mouse and human IL-28R chains contain similar docking sites for STAT2 recruitment and activation. Human IL-28R has a stretch of negatively charged residues close to the end of the intracellular domain. This region in the mouse IL-28R is significantly altered by a short insertion and substitution of several amino acid residues, resulting in a longer and more negatively charged region in the mouse receptor [14].

Several research groups including our own have examined the expression of IL-28 receptor complex components. The IL-10Rß chain is ubiquitously expressed, which can be explained by its function as part of several cytokine receptors. The one notable exception is the brain, where the IL-10Rß chain seems to be expressed at very low levels [42]. Therefore, the expression of the IL-28R chain should determine whether a cell is responsible to the type III IFNs or not $[12,13]$. The near relation of type III IFNs to type I IFNs and IL-10 initially suggested extensive effects of type III IFNs on various cell populations. Actually, Sheppard et al. observed at first that, using northern blot analysis, various organs variably expressed the major IL-28R transcript and therefore contain putative target cells in humans [13]. These organs include the adrenal gland and kidney, and those from the digestive (stomach, small intestine, colon and liver), respiratory (lung) and immune (spleen and thymus) systems, with the highest expression found in the pancreas, thyroid, skeletal muscle, heart, prostate, and testis [13]. Interestingly, most IL-28R mRNA-expressing tissues form outer body barriers and contain epithelial cells [43]. These quantitative results are in line with the data published by Kotenko et al. [9]. A pattern similar to that obtained in tissues using northern blot analysis was found in corresponding hematopoietic (HL-60 promyelocytic leukemia, K562 erythroleukemia, MOLT-4 T-cell leukemia and Raji B-cell leukemia) and nonhematopoietic (HeLa S3 cervical adenocarcinoma, Caco-2, SW480, HCT116, SW480 and DLD-1 colorectal adenocarcinoma, A549 lung alveolar cell carcinoma, LK-1 lung adenocarcinoma and G-361 melanoma) cell lines [12, 44, 45].

At present, it has been thought that the surface expression of IL-28R is more restricted relative to the type I IFN receptor although detailed information regarding with the expression level and cell distribution of the type III IFN specific receptor IL-28R is relatively limited. Therefore, whereas type I IFN signaling is observed for a broad spectrum of cell types, type III IFN signaling is generally weaker and more restrictive, which is correlated with a low expression of the IL-28R subunit of the type III IFN receptor. Actually, at the cellular level, B cell lymphoma Raji and hepatoma HepG2 cells respond well to type III IFNs. On the contrary, in HT1080 fibrosarcoma, Sw13 adrenal carcinoma cells and MCF-7 breast cancer cells, all of which respond to type I IFNs, no significant response to type III IFNs was observed [26]. Furthermore, in humans, primary bronchial epithelial cells and primary gastric epithelial cells are responsive to type III IFNs, whereas primary fibroblasts and umbilical vein endothelial cells do not express IL-28R and therefore are not responsive to type III IFNs (14 and our unpublished observation).

In mouse, IL-28R mRNA expression has been found in keratinocyte and lung fibroblast [14, 46]. In immune systems, our studies using RT-PCR did not detect any expression of IL-28R mRNA in primary spleen cells from C57BL/6 mice [43, 46]. Moreover, we could not detect any IL-28R expression in resting primary immune cells such as B cells and T cells [46]. Lasfar 
et al. also observed that primary lymphocytes and macrophages, the major players in specific antitumor immunity, are found to be unresponsive to type III IFN [14]. In accordance with the results obtained with primary immune cell subpopulations, corresponding cell lines (EL4 and P815) expressed IL-10Rß but not IL-28R [44]. On the contrary, Siebler et al. reported the opposite finding that the IL-28R mRNA is expressed in primary murine CD4 T cells [48]. In the case of NK cells, Murakami's group demonstrated the mRNA expression of IL-28R [47]. Further analyses are needed to determine the precise expression profile among immune cells. In general, tissues which are mainly composed of epithelia such as intestine, skin, or lung are the most responsive to type III IFNs. These data indicate that a key difference between the type I IFN and type III IFN systems could be the cell specificity of their respective receptor expression.

\section{Signal transduction of type III IFNs}

Signaling induced by a cytokine binding to type II cytokine receptor, whose extracellular parts commonly consist of tandem fibronectin type III domains and the cytoplasmic domain is associated with a tyrosine kinase of the Janus kinase (Jak) family, is known to occur primarily via the Jak/STAT pathway. Both IL-28R and IL-10Rß subunits are necessary to form a functional type III IFN receptor. The formation of the IL-28R-IL-10Rß ternary complex initiates signaling events by activating the transduction elements bound to the intracytoplasmic part of the two chains composed of functional type III IFN receptor. Type III IFNs induce the activation of a Jak/STAT signaling pathway leading to tyrosine phosphorylation of STAT1, STAT2, STAT3, STAT4 and STAT5 [12, 13, 22, 23, 49]. In structure, IL-28R is most closely related at the sequence level with the soluble class II cytokine receptor IL-22R $\alpha 2$, whereas a second type III IFN receptor chain IL-10Rß is commonly utilized by IL-10, IL-22 and IL-26 [38]. IL-10, IL-22 and IL-26 can stimulate STAT3 phosphorylation, and IL-22 and IL-26 have been shown to phosphorylate STAT1. On the other hand, only the type III IFN family induces tyrosine phosphorylation of STAT2. The characteristics to be able to phosphorylate STAT1, STAT2 and STAT3 are common to the type III IFN family and the type I IFNs. Thus, STAT2 activation has been, at present, restricted to type I IFNs and type III IFNs. From studies of IL-10 and IL-22 signal transduction, it is known that its short (82 amino acids) intracytoplasmic part binds tyrosine kinase Tyk2 but does not provide STAT recruitment sites [50]. Jak1 was shown to be critical in mediating IFN-induced STAT phosphorylation [22]. Thus, it is likely that, as for the type I IFN receptor system, Jak1 and Tyk2 are the two tyrosine kinases associated with the type III IFN receptor subunit and mediating STAT activation. STAT2 is specifically recruited in the ISGF3 transcription factor that translocates to the nucleus and drives the expression of the gene family carrying an ISRE sequence in their promoter. ISGF3 is formed by dimerization of STAT1 and STAT2 via SH2 phosphotyrosine interactions and association of the heterodimer with IRF9. Type III IFNs induce the formation of both ISGF3 and STAT1 homodimers, which are able to recognize ISRE and GAS sequences [12, 14, 23]. Among the IFN-induced genes, suppressor of cytokine signaling (SOCS) 1 and SOCS3 are involved in the negative regulation of type III IFN signaling [51, 52]. Overexpression of SOCS1 in hepatic cell lines inhibits type III IFN signaling as well [51]. Additionally, type I IFNs can activate a variety of signaling molecules and cascades, which may operate in concert with or independently of STATs. Similarly, type III IFNs were shown to activate ERK 1/2 and Akt in an intestinal epithelial cell line [44]. 


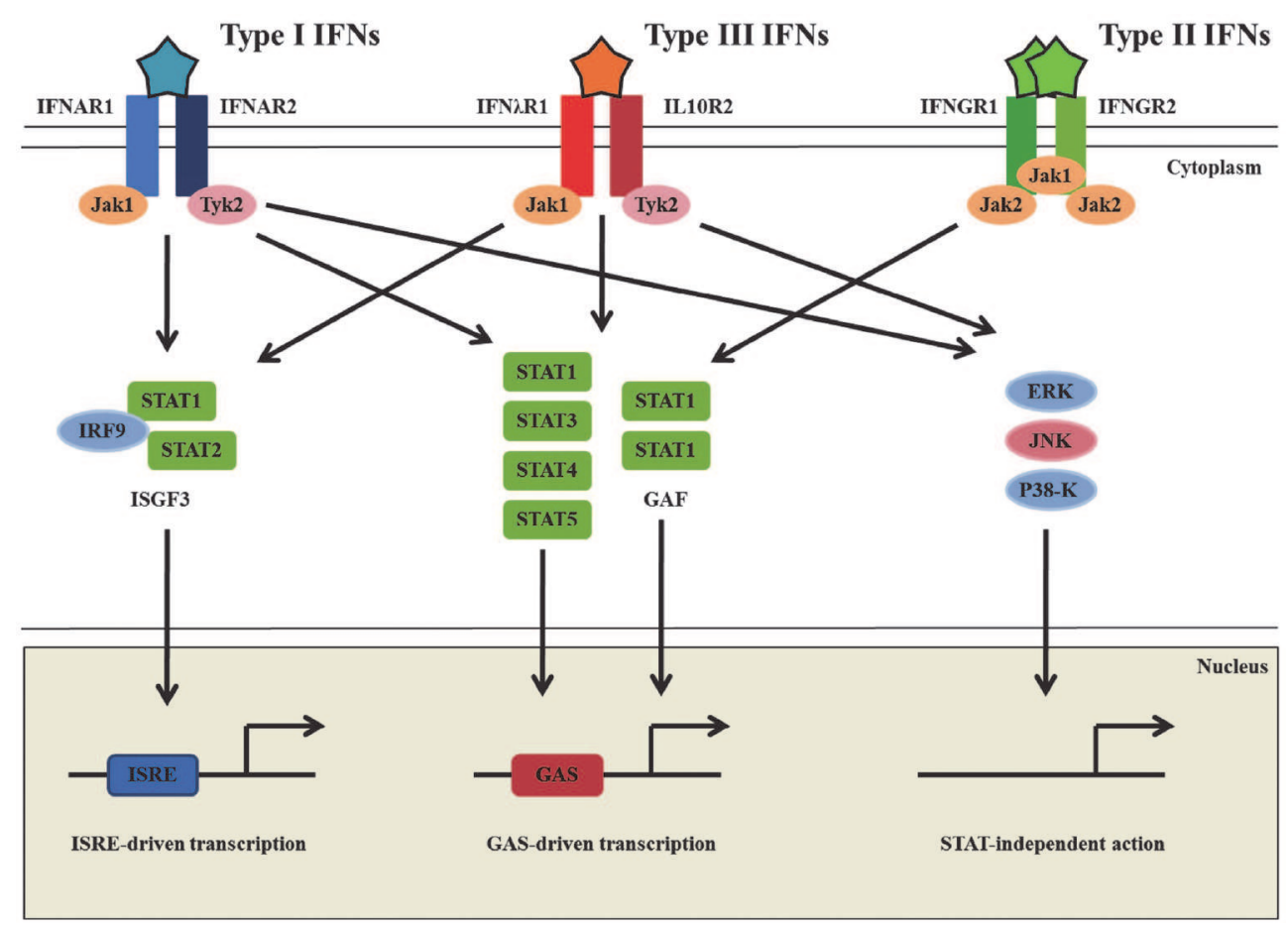

Fig. 1. Signaling pathways of type III IFNs, which activate similar intracellular signaling components and genes to type I IFNs.

\section{Direct antitumor activity of type III IFNs}

One of the most important properties of type I IFNs is their potential in cancer treatment. Type I IFNs represent the cytokines exhibiting the longest record of use in clinical oncology [53]. Even though today some new anticancer drugs somehow replaced type I IFNs in the treatment of certain hematological malignancies such as hairy cell leukemia and chronic myeloid leukemia, type I IFN therapy continues to be widely used in the adjuvant treatment of certain malignancies such as melanoma and renal cell carcinoma [54, 55]. As mentioned earlier, signaling components are shared between type I IFNs and type III IFNs. Therefore, based on the similar functional profiles with type I IFNs, it would be anticipated that type III IFNs would have redundant antitumor properties.

Several research groups have investigated the antitumor potential of type III IFNs. Until now, growth-inhibitory action of type III IFNs has been documented in certain histological types of human tumors such as neuroendocrine tumors [52], esophageal carcinoma [56], colorectal/intestinal carcinoma [51], hepatocellular carcinoma [16, 57, 58], lung adenocarcinomas [45], Burkitt's lymphoma [26], and melanoma [59]. These are summarized in Table 1. 


\begin{tabular}{|c|c|c|}
\hline Experimental system & Possible mechanism & References \\
\hline Human glioblastoma LN319 cell line & Growth inhibition & Meager et al. (2005) \\
\hline Human neuroendocrine BON1 tumor cells & Induction of apoptosis & Zitmann et al. (2006) \\
\hline Murine BW5147 thymoma cell line & Growth inhibition & Dumoutier et al. (2003) \\
\hline Human keratinocyte cell line $\mathrm{HaCaT}$, & Induced apoptosis, extended STAT activation, & Maher et al. (2008) \\
\hline Human fibrosarcoma $2 \mathrm{fTGH}$ cell line & prolonged ISG expression & Maher et al. (2008) \\
\hline Murine melanoma & Engaged host mechanisms to exert their antitumor functions & Lasfer et al. (2006) \\
\hline \multirow[t]{3}{*}{ Murine fibrosarcoma } & Induce innate and adaptive immune responses against tumors, & Numasaki et al. (2007) \\
\hline & including increase of IFN- $\gamma$ production and & \\
\hline & polymorphonuclear neutrophils, NK cells, and CD8 T cell activity & \\
\hline Murine melanoma, colon cancer & Induced tumor apoptosis and innate immune responses & Sato et al. (2006) \\
\hline Murine hepatoma & including IFN- $\gamma$, IL-12, NK cells and dendritic cells & Abushahba et al. (2010) \\
\hline
\end{tabular}

Table 1. Representative antitumor activity of type III IFNs

In vitro studies using multiple human cell lines including B cell lymphoma, hepatoma, neuroendocrine and colorectal tumor cell lines provide evidence that, in these lines, type III IFNs can induce $2^{\prime}-5^{\prime}$ oligoadenylate synthetase $\left(2^{\prime}, 5^{\prime}\right.$-OAS), which is involved in type I IFNinduced antiproliferative effects $[12,23,44]$. A study of ours also displayed that type III IFNs significantly suppressed in vitro growth of human NSCLC lines and markedly up-regulated mRNA expression of 2',5'-OAS in these lines [60]. Therefore, $2^{\prime}, 5^{\prime}$-OAS could, at least in part, contribute to the antiproliferative effect of type III IFNs. On the other hand, Brand et al. reported that the mRNA expression levels of protein kinase R (PKR) in intestinal epithelial cell lines remained unchanged after type III IFN treatment [44]. PKR mediates the antiproliferative function via inhibition of protein synthesis, and is also involved in the growth-inhibitory actions of type I IFNs. Additionally, we observed the same findings in human respiratory epithelial cell lines [60]. In contrast, in both hepatoma and B cell lines, type IIII IFNs mediated PKR gene induction [57]. Collectively, PKR could be involved in type III IFN-induced antiproliferative effect in a limited range of cell types.

Type I IFNs can exert a more direct negative regulatory effect on the cell cycle by specifically up-regulating expression of a number of cyclin-dependent kinase inhibitors (CKIs). Type I IFNs specifically enhance the expression level of p21Waf1/Cip1, which plays a crucial regulatory role in the progression from the G1 to $S$ phase [61]. Type I IFNs also increase expression of another CKI p15Ink4b that can complex specifically with Cdk4 [62]. A third protein p27Kip1 preferentially binds to cyclinE/Cdk2 complexes, and dissociation of the retinoblastoma gene product $(\mathrm{pRb})$ and the related pocket proteins (p107 and p130) is concomitantly suppressed [63]. $\mathrm{Rb}$ and the related pocket proteins, in their nonphosphorylated forms, interact strongly with the E2F family of transcription factors, thus inhibiting their activity [64]. Phosphorylation of $\mathrm{Rb}$ (and p107 or p130) normally releases E2F transcription factors, and permits transition from the G1 to $S$ phase.

Our recent study demonstrated that, in a panel of human esophageal carcinoma cell lines, the T.Tn cell line was susceptible to the apoptotic effects of type III IFNs, whereas type I IFNs elicited neither an antiproliferative nor a pro-apoptotic response [56]. p21 Waf1/Cip1 was initially expressed at high levels in T.Tn cells, and a large fraction of these cells were in the G0/G1 phase as a possible consequence of high levels of p21Waf1/Cip1 expression. In addition, our studies using multiple human NSCLC lines displayed elevated p21Waf1/Cip1 mRNA expression and, to a lesser extent, p27Kip1, but not p15 Ink4b, expression with type III IFN 
treatment, and that knockdown of p21Waf1/Cip1 with a p21Waf1/Cip1-specific double-stranded small inhibitory RNA (p21-siRNA) oligonucleotide largely attenuated the observed antiproliferative effect, suggesting the major role of $\mathrm{p} 21^{\text {Waf1/Cip1 }}$ in the growth-inhibitory function of type III IFNs [60]. Analysis of cell cycle distribution displayed that treatment of NSCLC lines with type III IFNs resulted in an accumulation of cell numbers in the G1 phase in a dose-dependent manner. This increase of the G1 population was accompanied by the reduction of S and G2 populations. Taken collectively, our results demonstrated that type III IFNs could induce cell cycle arrest at the G1 phase. These findings are in line with the result published earlier by Sato et al. [47].

Another important mechanism for type III IFNs to exert an antiproliferative effect was reported by Zitzmann's research group [52]. They demonstrated that treatment with type III IFN significantly suppressed the growth of human neuroendocrine BON1 tumor cells, but did not result in a significant accumulation in G1 phase [52]. Moreover, the same research group indicated that incubation with type III IFN significantly increased the amount of cleaved caspase-3- and poly(ADP-ribose)polymerase (PARP)-products in BON1 tumor cells [52]. In this case, treatment with type III IFN resulted in induction of apoptosis rather than in the interference of cell cycle progression. Moreover, Sato et al. reported that type III IFNs up-regulated surface expression of FAS, dephosphorylated $\mathrm{Rb}$ and activated both caspase-3 and caspase-7 in B16 melanoma cells, suggesting the promotion of apoptosis [47]. Our studies displayed that type III IFNs induced apoptosis in NSCLC cells by measuring DNA fragmentation and surface Annexin V expression when NSCLC cells were treated for relatively long periods [60]. In addition, Brand et al. indicated that type III IFNs did not influence FAS ligand-induced apoptosis but decreased cell proliferation in human intestinal epithelial cells [24].

Maher et al. demonstrated that type III IFN treatment induced a prolonged but overall stronger activation of STAT1 and STAT2 in the immortalized keratinocyte line HaCaT compared with IFN- $\alpha$ treatment [65]. Another distinctive difference was the induction of ISGs by IFN- $\alpha$, which peaked early and declined thereafter, whereas IFN- $\lambda$-induced ISGs levels peaked later but were sustained longer. A substantial growth inhibitory response, activation of caspase- 3 and caspase-7, and ultimately apoptosis ensued. Although IFN- $\alpha$ induced a modest antiproliferative effect, it did not promote apoptosis, suggesting that the prolonged STAT activity and subsequent induction and sustained expression of ISGs are what may have favored the activation of programmed cell death. Pretreatment of HaCaT cells with pan-caspase inhibitor benzyloxycarbonyl-Val-Ala-Asp (OMe) fluoromethylketone (Z-VAD-fmk) inhibited apoptosis, indicating a requirement for caspases in the promotion of type III IFN-induced cell death. The combination of IFN- $\alpha$ and type III IFN had additive an antiproliferative effect, suggesting that the distinct receptor complexes did not compete for available JAKs and STATs or, alternatively, the type I IFN and type III IFN signaled partially through alternative pathways. Li et al. [66] have also demonstrated that type III IFN signaling leads to the activation of apoptosis. In their model, a human HT29 colorectal adenocarcinoma cell line with ectopic expression of a chimeric IL-10Rß/IL-28R that binds IL-10, but signals through the intracellular domain of IL-28R, was shown to undergo apoptosis when treated with IL-10. The early response was antiproliferative but later switched to one of apoptosis as a drastic increase in the proportion of sub-G0 cells was observed. Caspase- 3 , caspase- 8 and caspase- 9 were cleaved and activated, and pretreatment 
with Z-VAD-fmk abrogated caspase-3 and caspase-9 activities, but did not block the deathinducing effect of IL-10, indicating the presence of an additional cell death pathways. Surprisingly, Z-VAD-fmk increased the cleavage of pro-caspase-9 into caspase-9. The strength of STAT1 activation by IL-10 through the chimeric receptor was more robust than treatment with type III IFN that signaled through the endogenous IL-28R complex. Of note, HT29 cells express low levels of IL-28R and can respond to type III IFN by up-regulating MHC class I expression, but they are not growth inhibited by type III IFN. This raises an important point as it suggests that a sufficient number of cell surface IL-28R must be expressed and engaged for type III IFN to induce an antiproliferative effect. These studies are in agreement with our findings and strongly suggest that the strength of type III IFN signaling through STAT activation may be the determining factor that favors an apoptotic response.

Antiproliferative and pro-apoptotic effects of type III IFN can be augmented when used in combination with chemotherapy drugs. Lesinski et al. reported that co-treatment of F0melanoma cells with proteasome inhibitor Bortezomib and type III IFN synergistically increased cell death, similar to the combination of IFN- $\alpha$ and Bortezomib [67]. We also observed that the combination of 5-fluorouracil (5-FU) or cisplatin (CDDP) with type III IFN drastically inhibited cell growth of the esophageal carcinoma cell lines [56]. When esophageal carcinoma cell lines TE-11, YES-5 and T.Tn cells, which were sensitive to antiproliferative effect of type III IFN IL-29, were cultured with various doses of 5-FU or CDDP, IL-29 significantly enhanced the cytotoxicity of 5-FU or CDDP. This combinatory effect was additive irrespective of the agents. In contrast, IL-29 scarcely influenced the cytotoxicity of 5-FU or CDDP in normal and Het-1A cells, whereas IFN- $\alpha$ enhanced the sensitivity of normal and Het-1A cells to 5-FU or CDDP.

Our recent study demonstrated that antiproliferative effects of type III IFNs could be also enhanced when combined with type I IFN IFN- $\alpha$ [60]. Treatment with interferon combination of type III IFN and type I IFN increased p21Waf1/Cip1 expression, and induced apoptotic cell death more efficiently, and consequently exerted an additive growthinhibitory effect on NSCLC lines in vitro. In addition, interferon combination therapy of IL29 and IFN- $\alpha$ inhibited in vivo growth of xenogeneic NSCLC OBA-LK1 tumors more effectively than individual regent alone [60].

One of the important mechanisms of antitumor activities of type I IFNs is inhibition of tumor-induced angiogenesis [68]. Type I IFNs can inhibit a number of steps in the angiogenic processes, including proliferation and migration of vascular endothelial cells [69, 70, 71, 72]. Type I IFNs can also affect the expression of several angiogenic factors, including vascular endothelial growth factor (VEGF) [73], bFGF [74], IL-8 [75], and collagenase type IV in tumor cells and surrounding stroma cells [76]. Indeed, systemic therapy with the use of recombinant type I IFNs produces antiangiogenic effects in vascular tumors including hemangioma [77], Kaposi's sarcoma [78], melanoma [79], and bladder carcinoma [80].

In contrast to type I IFNs, there have been no reports demonstrating type III IFNs possess antiangiogenic activities. One of the key differences reported between the type I IFN and type III IFN systems is in the expression of their respective receptor subunits. For example, vascular endothelial cells express IFN- $\alpha$ R $\alpha$, IFN- $\alpha$ Rß and IL-10Rß, but not IL-28R, on the cell 
surface [14]. Therefore, vascular endothelial cells appear to be, in general, unresponsive to type III IFNs. In addition, type III IFN treatment up-regulated, not suppressed, the secretion of proangiogenic cytokine IL-8 from human colon cancer cells [24]. Additionally, exposure of human macrophages to type III IFN IL-29 significantly induces IL-8 production [81]. In contrast, Pekarek et al. reported that, using human peripheral blood mononuclear cells, type III IFN member IL-29 elevated mRNA expression levels of three chemokines, monokine induced IFN- $\gamma$ (MIG), IFN- $\gamma$ inducible protein 10 (IP-10) and IFN- $\gamma$ inducible T cell $\alpha$ chemoattractant (I-TAC) in the absence of other stimuli [82]. These factors are members of the ELR- subfamily of CXC chemokines and display potent inhibitory effects on angiogenesis. In our xenogeneic NSCLC tumor models, daily intratumoral administration of IL-29 significantly suppressed in vivo tumor growth, but did not affect the tumor microvascular density [78]. Taken collectively, it is still now unknown whether type III IFNs possess antiangiogenic properties like type I IFNs. Further detailed analyses are needed to elucidate the biological role of type III IFN in angiogenesis.

\section{Induction of antitumor immunity by type III IFNs}

Several laboratories including ours carried out an ensemble of studies where the mouse type III IFN IL-28A gene was transduced into different types of mouse tumor cells and in vivo behavior of genetically modified cells constitutively secreting IL-28A was evaluated after injection into immunocompetent syngeneic mice [14, 46, 47]. In these experiments, a gene therapy approach was introduced to investigate whether type III IFNs may possess antitumor actions instead of systemic therapy because cytokine gene therapy has many advantages in comparison with systemic administration of cytokine. Systemic delivery of cytokines at pharmacologic doses results in a high concentration of cytokines in the circulation and often in suboptimal levels in tissues at the site of tumors. In contrast, cytokine gene transfer allows the localized expression of the cytokine at the targeted sites, avoiding deleterious side effects and resembling the paracrine mode of action of cytokines, which are produced in high amounts at the site of tumors and act on the immune system by providing transient signals between cells to generate effector responses.

Ahmed et al. first investigated whether the constitutive expression of IL-28A at the tumor site may affect the tumorigenicity of B16 melanoma cells, which are responsive to type III IFNs and classified as a low immunogenicity [14]. This study provided initial evidence that the tumorigenicity of B16 cells producing IL-28A in immunocompetent mice is highly impaired or completely abolished, and that the inhibition of tumor establishment is dependent on the amount of IL-28A released by the genetically modified tumor cells [14]. Whereas $50 \%$ of mice injected with B16 clone producing 100 to $150 \mathrm{ng}$ of IL-28A for 24 hours per $10^{6}$ cells developed tumors, $100 \%$ of animals injected with B16 clone releasing 1 to $5 \mathrm{ng}$ of IL-28A developed tumors. When B16 clone, which produced IL-28A but was resistant to the antiproliferative effect of IL-28A, was used to examine whether the antitumor effect of IL-28A was due to direct action on B16 cells or mediated by a host response, type III IFNunresponsive B16 clone expressing IL-28A displayed reduced tumorigenicity and repressed the growth of parental B16 cells in vivo to a level comparable to IL-28A-responsive B16 cells, providing evidence that host-defense mechanisms play a major role in mediating type III IFN-induced antitumor activity in vivo [14]. In this tumor model, about $10 \%$ mice, which 
rejected B16 melanoma cells producing IL-28A, survived the subsequent parental B16 tumor challenge, suggesting the failure of development of a strong long-lasting immune memory [14]. Taken together with the findings that tumor-infiltrating immune cells were not observed in tumor tissues from B16 cells secreting IL-28A and mouse primary lymphocytes and macrophages are unresponsive to type III IFNs, it was proposed as one of the possible mechanisms that IL-28A produced by genetically modified B16 cells could first act on neighboring keratinocytes and other tumor stromal cells, and could inhibit their tumorsupportive function, leading to the reduced tumorigenicity in the B16 melanoma tumor model [14].

The antitumor therapeutic potential of type III IFN gene transfer into experimental tumors was further evaluated in animal models by another research group using various approaches, comprising both the use of genetically modified cells and in vivo delivery of type III IFN gene via injection of naked plasmid DNA. To examine the antitumor potency of type III IFNs in vivo, Sato et al. transfected B16/F0 mouse melanoma cells with IL-28A cDNA, which resulted in in vitro growth inhibition and increased caspase- 3 and caspase-7 activity [47]. Transduction of IL-28A increased p21 Waf1/Cip1 levels and decreased phosphorylation of $\mathrm{Rb}$ (Ser ${ }^{780}$ ), suggesting a mechanism for the observed cell arrest. In addition, B16/F0 cells producing IL-28A did not form pulmonary metastasis when injected into C57BL/6 mice. Histological examination of the lungs revealed cellular infiltrates and NK cells were demonstrated to be responsible for the major part of antitumor effect of type III IFN [47]. Moreover, the biological effects of ectopic IL-28A, secreted by the injected tumor cells, on the host's immune response have been thoroughly investigated. Targeting of Colon 26 liver metastatic lesions by hydrodynamic gene delivery of plasmid DNA encoding mouse IL-28A led to marked reduction of liver metastatic foci along with survival advantages [47]. By studying the in vivo turnover of different lymphocyte subsets in mice injected with IL-28 plasmid DNA, the number of NK cells and NKT cells in the liver markedly increased [47]. In contrast, B16 lung metastases were not successfully treated by hydrodynamic injection of IL28A expression plasmid, indicating that the local delivery of type III IFN to target sites is necessary for the control of metastatic tumor growth, and that type III IFN-induced systemic cytotoxic T cell (CTL) response is relatively weak in this tumor model [47].

Despite the type III IFN-resistant phenotype, successful induction of antitumor response following type III IFN IL-28A gene transfer was subsequently confirmed in the MCA205 tumor model [46]. We observed that in vivo growth of MCA205 producing IL-28A was efficiently inhibited by an IL-28A-elicited host-mediated immune response [46]. In this tumor model, the tumorigenic behavior of MCA205 cells producing either type I IFN IFN- $\alpha$ or type III IFN IL-28A was compared after subcutaneous injection. IFN- $\alpha$-secreting MCA205 (MCA205IFN- $\alpha$ ) cells were rejected efficiently compared to IL-28A-producing MCA205 (MCA205IL-28) cells, which exhibited only a delay of tumor growth [46]. This finding implicated that the potency of the antitumor activity of IL-28A might be slightly lower than that of IFN- $\alpha$ although MCA205IL-28 cells secreted approximately 3-fold less cytokine than did MCA205IFN- $\alpha$ cells [43]. IFN- $\alpha$ in contrast to IL-28A displayed direct biological effects on MCA205 cells, including enhancement of the MHC class I antigen expression, suggesting that IFN- $\alpha$, but not IL-28A, can directly influence the immunogenicity of MCA205 cells.

In regard to the cellular antitumor mechanisms of IL-28A, the findings in mice selectively depleted of various immune cell populations indicated that CD8 T cells play an important 
role in IL-28A-mediated antitumor immunity in the MCA205 tumor model because the protective effect was partially abolished in CD8 T cell-depleted animals [46]. This finding is in clear contrast with the result obtained in the B16 melanoma tumor model, in which depletion of CD8 T cells had no consequence on the tumor growth rate [47]. Additionally, in this tumor model, local secretion of IL-28A by tumor cells induced more powerful tumorspecific cytotoxic T cells against parental MCA205 cells [46]. This is consistent with the observed dense infiltration of CD8 T cells into tumor tissues from MCA205IL-28 cells. However, primary mouse CD8 T cells are not expressing IL-28R on the cell surface and are found to be unresponsive to IL-28A treatment [46]. This characteristic of type III IFNs is in clear contrast with that of type I IFNs, which can directly act on T cells [80]. On the contrary, the expression of mRNA for IL-28R is clearly detected in Con A-stimulated mouse T cells, suggesting that the activated mouse CD8 $\mathrm{T}$ cells might possess the ability to respond to type III IFNs [46]. However, IL-28 does not have ability to directly enhance the cytotoxic activity of CTLs [46]. A recent report by Jordan et al. indicated that type III IFN IL-29 influences the cytokine production by Con A-stimulated human T cells, which is isolated from peripheral blood mononuclear cells [81]. IL-28A also displayed the biological function to induce chemokine secretion by mouse lung fibroblasts [46]. Taken together, one possible mechanism, by which IL-28A elicits CD8 T cell responses, is proposed to be that IL-28A first stimulates CD8 T cells indirectly through induction of other cytokines and chemokines by surrounding cells including stromal fibroblasts and keratinocytes, and subsequently acts on activated T cells directly [46]. Therefore, the detailed mechanisms that underlie this CD8 T cell-dependent antitumor action by type III IFNs remain to be elucidated and will require further experimental analyses.

A slower growth rate of MCA205IL-28 tumors in CD4 T cell-depleted mice was consistently observed, implicating that CD4 $\mathrm{T}$ cells rather inhibit IL-28A-induced antitumor response [46]. Both CD4 T cells and CD8 T cells have been described to be important for the efficient induction of antitumor cellular immunity $[84,85]$. This unexpected finding that CD4 T cells are not required for the antitumor activity of IL-28A is not in agreement with the notion that CD4 $\mathrm{T}$ cell help is necessary for the full activation of naive CD8 $\mathrm{T}$ cells [86]. However, a similar inhibitory effect of CD4 $\mathrm{T}$ cells has been previously reported in IL-12- or IL-23transduced CT26 tumor model $[87,88]$. These findings may be possibly explained by taking into account the $\mathrm{CD} 4{ }^{+} \mathrm{CD} 25^{+} \mathrm{T}$ regulatory cells [89]. With regard to the relation between type III IFNs and $\mathrm{CD}_{4}{ }^{+} \mathrm{CD} 25^{+} \mathrm{T}$ regulatory cells, Mennechet et al. reported that IL-28A promotes the generation of partially mature DCs, which display a tolerogenic phenotype [90]. Namely, type III IFN-matured DCs with the ability to migrate lymph nodes express high levels of MHC class I and II but low levels of co-stimulatory molecules [90]. These type III IFN-treated DCs specifically induced IL-2-dependent proliferation of a $\mathrm{CD}^{+}{ }^{+} \mathrm{CD} 25^{+} \mathrm{Foxp}^{+} \mathrm{T}$ regulatory cell population in culture, which is thought, in general, to result in suppression of the antitumor immune response [89]. Therefore, type III IFN-treated DCs can stimulate the proliferation of pre-existing $\mathrm{CD} 4{ }^{+} \mathrm{CD} 25^{+} \mathrm{T}$ regulatory cells in the presence of IL-2 and inhibit efficient antitumor immunity. Of particular interest, these findings provide another important evidence that type I IFNs and type III IFNs can exert distinct biological effects on DC differentiation, phenotype and function.

The finding that, in the MCA205 tumor model, IL-28A-elicited antitumor response was partially abrogated in NK cell-depleted mice strongly implied that NK cells play an 
important role in the antitumor activity of IL-28A [46]. This finding is consistent with the result demonstrated by Sato et al. using the tumor model of B16 melanoma [47]. However, the surprising finding is that IL-28A is unable to directly enhance NK cell cytolytic activity both in vitro and in vivo [46]. This biological feature of type III IFNs on NK cells is in sharp contrast to type I IFNs, which markedly promote NK cell-mediated cytotoxicity in culture and in vivo [91]. In addition, IL-28A does not have capability to directly stimulate the growth of NK cells in culture [46]. On the other hand, IL-28A administration into SCID mice significantly expanded splenic NK cells depending on the dose of injection, and expression of IL-28A in the liver increased the number of hepatic NK cells [46, 47]. In the case of type I IFNs, exposure to type I IFNs is closely associated with NK cell blastogenesis and proliferation, but not IFN- $\gamma$ expression in vivo [92]. Immunoregulatory effect of type I IFNs to elicit the expression of IL-15 in mouse cell populations has been proposed to contribute to the induction of NK cell proliferation [93]. In contrast, the detailed mechanisms for type III IFN-induced proliferation of NK cells in vivo remain largely unknown [46, 47]. Nonetheless, type III IFNs appear to augment NK cell-mediated in vivo antitumor activity via increasing the total number of NK cells [46]. Another possible explanation of underlying mechanisms is that IL-28A, like IL-21 [94], could enhance the cytolytic activity of NK cells previously activated by stimulators such as other cytokines and chemokines, but could not induce cytotoxic activity in resting NK cells. Recently, Abushahba et al. reported that DCs are involved in type III IFN-elicited NK cell activation [95]. DCs stimulated by type III IFNs secreted more amounts of bioactive IL-12, which subsequently activated NK cells [95]. Thus, there is a possibility that type III IFN activates NK cells indirectly via stimulation of DCs.

Polymorphonuclear neutrophils contribute, in some way, to the suppression of tumor growth in the MCA205 tumor model as shown by the fact that treatment with a monoclonal antibody $(\mathrm{mAb})$ against Gr-1 partially abrogated IL-28A-elicited tumor growth suppression [46]. Polymorphonuclear neutrophils can be frequently involved in the generation of CD8 T cell-mediated antitumor responses [96]. Notably, evidence that polymorphonuclear neutrophils may be important for the induction of an antitumor immunity has already been suggested [96], and a specific role for polymorphonuclear neutrophils in the development of CD8 T cell-mediated antitumor responses was also demonstrated [97]. However, little is known about the biological effects of type III IFNs on this cell population. Especially, the direct biological activity of type III IFN on polymorphonuclear neutrophils remains largely to be elucidated. In contrast, type III IFNs are able to positively regulate expression of several chemokines, which activates polymorphonuclear neutrophils. This was first demonstrated in the human in culture systems using peripheral mononuclear cells [82]. Indeed, type III IFN IL-29 induces IL-8 secretion from human peripheral mononuclear cells, especially macrophages, suggesting that type III IFNs at least have capabilities to stimulate polymorphonuclear neutrophils indirectly via induction of chemokines including IL-8 [82].

The fact that MCA205IL-28 cells were more tumorigenic in IFN- $\gamma$ KO mice than in syngeneic immunocompetent mice indicated that IFN- $\gamma$ is involved in IL-28A-mediated antitumor responses [46]. Type II IFN IFN- $\gamma$ is a pleiotropic cytokine that can act on both tumor cells and host immunity $[98,99]$. IFN- $\gamma$ directly inhibits proliferation of some tumor cells and indirectly suppresses tumor growth in vivo by activating NK cells and macrophages and inducing angiostatic chemokines such as MIG and IP-10 with consequent inhibition of tumor angiogenesis [100]. Nevertheless, abrogation of IFN- $\gamma$ could not completely attenuate 
the antitumor action of IL-28A, indicating that IFN- $\gamma$-independent pathways are also involved in IL-28A-mediated antitumor activity [46]. In contrast, based on the finding obtained from the animals treated with neutralizing anti-IL-12 p40 mAb, IL-12 is not involved in type III IFN-mediated antitumor activity [46]. Now, little is known about the relation between type III IFNs and IL-12 expression. On the other hand, in contrast to the IFN- $\gamma$ promotion of IL-12 expression, type I IFNs can negatively regulate IL-12 expression in DCs and monocytes [101, 102]. Although type III IFNs display overlapping biological activities with type I IFNs, type III IFNs may have ability to up-regulate IL-12 expression by human macrophages and mouse DCs, in contrast to type I IFNs [95, 103]. Now, further analyses are needed to determine the relation between type III IFNs and IL-12 expression. In addition, other cytokines including IL-17 and IL-23 are not required for IL-28A-induced antitumor activity [46].

IFN- $\gamma$ is partially involved in type III IFN-mediated antitumor action, whereas a wide range of doses of IL-28A exert no direct effects on the release of IFN- $\gamma$ by NK cells and CD8 T cells stimulated with or without anti-mouse CD3 mAb in culture [46]. In contrast, IL-28A induces IFN- $\gamma$ release by primary CD4 T cells stimulated with anti-mouse CD3 mAb or co-stimulated with anti-mouse CD3 mAb plus anti-mouse CD28 mAb [48]. This biological effect of IL-28A on IFN- $\gamma$ secretion appears to be dose-dependent [48]. In addition, this ability of IL-28A to induce IFN- $\gamma$ secretion by CD4 T cells is T-bet dependent [48]. However, in contrast to IL-12, daily administration of IL-28A into C57BL/ 6 mice for 3 consecutive days could not induce measurable serum IFN- $\gamma$ levels in vivo [46]. Therefore, the pathway from type III IFNs to IFN- $\gamma$ expression in the mouse remains to be elucidated.

Abushaba et al. recently reported that, using BNL hepatoma line which was resistant to IL28A treatment due to the lack of IL-28R expression, IL-28A secreted by tumor cells reduced the tumorigenicity and retarded the growth kinetics [95]. In this tumor model, NK cells were predominant effector cells activated indirectly by IL-28A. In addition, the enhanced cytotoxicity against BNL cells mediated by IL-28A was largely dependent on IL-12 produced by DCs and subsequently produced IFN- $\gamma$ by NK cells [95]. In fact, both myeloid and plasmacytoid DCs responded well to type III IFNs and secreted IL-12 [95]. Therefore, further analyses are needed to elucidate the precise role of IL-12 and IFN- $\gamma$ in type III IFNinduced antitumor immune responses.

In human systems, with regard to the induction of IFN- $\gamma$ secretion, a recent report by Jordan et al. described that type III IFN IL-29 treatment induced a modest elevation of released IFN$\gamma$ in T cells, following stimulation with Con A or in a mixed-lymphocyte reaction (MLR) [81]. Thus, there is a readily accessible and functional pathway from type III IFNs to IFN- $\gamma$ expression in humans that does not appear to be fully operational in the mouse system. In the case of type I IFNs, there are positive effects on human T cell IFN- $\gamma$ expression following stimulation with particular molecules including polyI:C [104]. Furthermore, Liu et al. demonstrated that, in humans, monocyte-derived macrophages activated by TLR responded to IL-29 stimulation and secreted IL-12 and TNF- $\alpha$, whereas monocyte and monocytederived DCs did not due to the lack of surface IL-28R expression [103]. Monocyte-derived macrophages stimulated with IL-29 responded well to IFN- $\gamma$ stimulation, and produced significantly more IL-12 through up-regulated IFN- $\gamma$ R1 expression, whereas this activity was not found in IL-28A and IL-28B [103]. In clear contrast, monocyte-derived macrophages stimulated with IFN- $\alpha$ down-regulated surface IFN- $\gamma$ R1 expression [103]. 
Combination therapy with local production of IL-28A by genetically modified tumor cells and systemic administration of IL-12 protein has a synergistic antitumor effect without apparent deleterious side effects, suggesting possible advantages in this combined therapy [46]. IL-28A secretion or administration of IL-12 rejected none, whereas the combination of two manipulations resulted in rejection of MCA205 cells in $40 \%$ of mice and dramatically delayed tumor growth in the remainder [46]. The presence of protective antitumor immunity in the surviving mice indicates that the effectiveness of this combination strategy extends beyond initial rejection of MCA205IL-28 cells to the development of protective longlasting immunity, which is specific for the initial MCA205 tumor [46]. Studies with lymphocyte subset ablation and using IFN- $\gamma \mathrm{KO}$ mice indicated that rejection of MCA205 tumor cells brought about by the synergistic effects of IL-28A and IL-12 is mediated by systemic antitumor response that is dependent on the presence of both NK cells and CD8 T cells, but not CD4 T cells, and involves IFN- $\gamma$ [46]. As mentioned above, type III IFNs themselves appear to have, if any, a limited capability to stimulate IFN- $\gamma$ secretion in mouse systems, whereas type III IFN significantly enhances IL-12-mediated IFN- $\gamma$ secretion by CD4 $\mathrm{T}$ cells stimulated with anti-mouse $\mathrm{CD} 3 \mathrm{mAb}$ in vitro, and increases serum IFN- $\gamma$ concentration and the total number of spleen cells as compared with IL-12 alone in C57BL/6 mice $[46,48]$. This biological effect of type III IFN on IL-12-induced IFN- $\gamma$ expression is common with type I IFN. It has been reported that there is a modest type I IFN effect on IL12 induction of IFN- $\gamma$ production by mouse cells in culture [105]. Thus, the enhancement of the antitumor effect by combination therapy of type III IFN IL-28A and IL-12 appears to be, at least in part, dependent on increased IFN- $\gamma$ production [46].

A surprising finding was that the enhancement of the antitumor effect of IL-28A by systemic treatment with IL-12 protein is found even in IFN- $\gamma$ KO mice [46]. This finding provides evidence that IL-12 is able to enhance antitumor action of type III IFN through IFN- $\gamma$ independent pathways [46]. Of interest, there have been lots of reports describing that antitumor effect of systemic administration of IL-12 protein into mice is largely abrogated in IFN- $\gamma$ KO mice [106]. On the contrary, in IFN- $\gamma$ KO mice, IL-12 produced by genetically modified tumor cells is able to induce production of other mediators, instead of IFN- $\gamma$, including GM-CSF by both CD4 T cells and CD8 T cells and IL-15 by non-lymphoid cells, which are critically involved in IL-12-induced antitumor activity in IFN- $\gamma \mathrm{KO}$ mice in the C26 tumor model [107, 108]. Thus, IL-12-elicited enhancement of type III IFN-mediated antitumor activity may be due to an indirect effect via the mediators including GM-CSF and IL-15, which are induced by IL-12 in IFN- $\gamma \mathrm{KO}$ mice. In addition, type I IFNs have a biological action to up-regulate expression of the heterodimeric high-affinity receptor for IL12 comprised of $B 1$ and $B 2$ chains $[109,110]$, and to enhance the biological effects of IL- 12 . Thus, it was proposed that, like type I IFNs, type III IFNs may enhance IL-12-mediated biological effects on NK cells and T cells via up-regulation of IL-12 receptor expression, leading to augmentation of the antitumor activity.

\section{Clinical application of type III IFNs}

From in vitro and in vivo studies using human and murine tumor cells, it has become clear that antitumor effects of type III IFN are less effective compared with those of type I IFN. Therefore, the clinical usage of type III IFNs as anticancer drugs may be relatively limiting. However, one of the suggested benefits of potentially applying type III IFNs to the 
treatment of cancer is the restricted expression of its specific receptor subunit IL-28R. In this situation, the weaker magnitude of the activity of type III IFNs as compared with that of type I IFNs is anticipated to avoid causing the severe adverse side effects or to reduce the toxicity often observed in patients treated with type I IFNs such as fever, fatigue, hematological toxicity, anorexia, and depression. Actually, animal studies and clinical trials to treat patients with chronic hepatitis $\mathrm{C}$ virus $(\mathrm{HCV})$ infection have displayed very few toxic side effects in response to Peg-IFN- $\lambda 1$ administration at concentrations that elicit comparable antiviral effects as observed with Peg-IFN- $\alpha$ treatment. Additionally, type III IFNs cooperate with type I IFNs to inhibit in vitro and in vivo NSCLC tumor growth additively via, at least in part, enhanced p21Waf1/Cip1 expression and induction of apoptosis [60]. Therefore, although the cooperative antitumor activity of type III IFN and type I IFN against various histological types of tumors has not been fully evaluated, our findings raise the possibility that the interferon combination therapy of type III IFN and type I IFN may not only surpass the therapeutic outcome of IFN- $\alpha$ monotherapy, but also reduce the side effects by decreasing the daily dose of IFN- $\alpha$.

\section{Conclusions and perspectives}

Since the discovery of the type III IFN and IL-28R systems in 2003, this novel cytokine family has been demonstrated to have multiple biological actions, which have some similarities with those of type I IFNs. In this chapter, we have reviewed recent studies, describing the potential of type III IFNs in the treatment of cancer. A lot of reports investigating the antitumor activity of type III IFNs in in vitro and in vivo studies provided clear evidence that type III IFN has multiple biological activities to elicit direct and indirect antitumor activities. However, to date much more remains to be elucidated, not only in terms of mechanisms responsible for the antitumor responses observed in mouse tumor models but also, if any, in terms of adverse effects. The exploitation of recent findings on the antitumor action of type III IFNs will require more detailed information about the biological activities against various cell types. Especially, the biological actions of type III IFNs against different lymphoid subpopulations, including NK cells, T cells, macrophages and DCs, have to be fully clarified. In addition, only few selected points which are specifically important in tumor therapy with type III IFNs, taking into consideration not only type III IFN monotherapy but also combination therapy of type III IFN and chemotherapeutic agent or of type III IFN and type I IFN, which may cooperate for the generation of long-lasting control of tumor growth will be emphasized. Furthermore, separate attention should be paid to the role of endogenous type III IFN in the natural immune control of tumor growth using recently generated IL-28R gene knockout mice [111]. At present, the potential of type III IFNs in a clinical application to cancer therapy is unknown. Further studies will provide a better understanding of whether subtle differences in gene expression induced by type III IFNs relative to type I IFNs may reduce the adverse side effects and increase the efficacy typically seen in type I IFN cancer therapy.

\section{References}

[1] Isaacs, A., and Lindenmann, J. 1987, J. Interferon Res., 7, 429.

[2] Weissmann, C., and Weber, H. 1986, Prog. Nucleic Acid. Res. Mol. Biol., 33, 251.

[3] Pestka, S., Langer, J.A., Zoon, K.C., and Samuel, C.E. 1987, Annu. Rev. Biochem., 56, 727. 
[4] Pestka, S., Krause, C.D., and Walter, M.R. 2004, Immunol. Rev., 202, 8.

[5] Roberts, R.M., Liu, L., Guo, Q., Leaman, D., and Bixby, J. 1998, 18, 805.

[6] LaFleur, D.W., Nardelli, B., Tsareva, T., Mather, D., Feng, P., Semenuk, M., Taylor, K., Buergin, M., Chinchilla, D., Roshke, V., Chen, G., Ruben, S.M., Pitha, P.M., Coleman, T.A., and Moore, P.A. 2001, J. Biol. Chem., 276, 39765.

[7] Peng, F.W., Duan, Z.J., Zheng, L.S., Xie, Z.P., Gao, H.C., Zhang, H., Li, W.P., and Hou, Y.D. 2007, Protein Expr. Purif., 53, 356.

[8] Adolf, G.R. 1990, Virology, 175, 410.

[9] Belardelli, F., Ferrantini, M., Proietti, E., and Kirkwood, J.M. 2002, Cytokine Growth Factor Rev., 13, 119.

[10] Pfeffer, L.M., Dinarello, C.A., Herberman, R.B., Williams, B.R., Borden, E.C., Bordens, R., Walter, M.R., Nagabhushan, T.L., Trotta, P.P., and Pestka, S. 1998, Cancer Res., 58, 2489.

[11] Belardelli, F., and Gresser, I. 1996, Immunol. Today, 17, 369.

[12] Kotenko, S.V., Gallagher, G., Baurin, V.V., Lewis-Antes, A., Shen, M., Shah, N.K., Langer, J.A., Sheikh, F., Dickensheets, H., and Donnelly, R.P. 2003, Nat. Immunol., 4,69 .

[13] Sheppard, P., Kindsvogel, W., Xu, W., Henderson, K., Schlutsmeyer, S., Whitmore, T.E., Kuestner, R., Garrigues, U., Birks, C., Roraback, J., Ostrander, C., Dong, D., Shin, J., Presnell, S., Fox, B., Haldeman, B., Cooper, E., Taft, D., Gilbert, T., Grant, F.J., Tackett, M., Krivan, W., McKnight, G., Clegg, C., Foster, D., and Klucher, K.M. 2003, Nat. Immunol., 4, 63.

[14] Lasfar, A., Lewis-Antes, A., Smirnov, S.V., Anantha, S., Abushahba, W., Tian, B., Reuhl, K., Dickensheets, H., Sheikh, F., Donnelly, R.P., Raveche, E., and Kotenko, S.V. 2006, Cancer Res., 66, 4468.

[15] Onoguchi, K., Yoneyama, M., Takemura, A., Akira, S., Taniguchi, T., Namiki, H., and Fujita, T. 2007, J. Biol. Chem., 282, 7576.

[16] Ank, N., West, H., Bartholdy, C., Eriksson, K., Thomsen, A.R., and Paludan, S.R. 2006, J. Virol., 80, 4501.

[17] Coccia, E.M., Severa, M., Giacomini, E., Monneron, D., Remoli, M.E., Julkunen, I., Cella, M., Lande, R., and Uzé, G. 2004, Eur. J. Immunol., 34, 796.

[18] Tissari, J., Sirén, J., Meri, S., Julkunen, I., and Matikainen, S. 2005, J. Immunol., 174, 4289.

[19] Sirén, J., Pirhonen, J., Julkunen, I., and Matikainen, S. 2005, J. Immunol., 174, 1932.

[20] Ank, N., Iversen, M.B., Bartholdy, C., Staeheli, P., Hartmann, R., Jensen, U.B., DagnaesHansen, F., Thomsen, A.R., Chen, Z., Haugen, H., Klucher, K., and Paludan, S.R. 2008, J. Immunol., 180, 2474.

[21] Langer, J.A., Cutrone, E.C., and Kotenko, S. 2004, Cytokine Growth Factor Rev., 15, 33.

[22] Dumoutier, L., Lejeune, D., Hor, S., Fickenscher, H., and Renauld, J.C. 2003, Biochem. J., $370,391$.

[23] Dumoutier, L., Tounsi, A., Michiels, T., Sommereyns, C., Kotenko, S.V., and Renauld, J.C. 2004, J. Biol. Chem., 279, 32269.

[24] Brand, S., Beigel, F., Olszak, T., Zitzmann, K., Eichhorst, S.T., Otte, J.M., Diebold, J., Diepolder, H., Adler, B., Auernhammer, C.J., Göke, B., and Dambacher, J. 2005, Am. J. Physiol. Gastrointest. Liver Physiol., 289, G960.

[25] Osterlund, P.I., Pietilä, T.E., Veckman, V., Kotenko, S.V., and Julkunen, I. 2007, J. Immunol., 179, 3434. 
[26] Zhou, Z., Hamming, O.J., Ank, N., Paludan, S.R., Nielsen, A.L., and Hartmann, R. 2007, J. Virol., 81, 7749.

[27] Sirén, J., Pirhonen, J., Julkunen, I., and Matikainen, S. 2005, J. Immunol., 15, 1932.

[28] Osterlund, P., Veckman, V., Sirén, J., Klucher, K.M., Hiscott, J., Matikainen, S., and Julkunen, I. 2005, J. Virol., 79, 9608.

[29] Matikainen, S., Sirén, J., Tissari, J., Veckman, V., Pirhonen, J., Severa, M., Sun, Q., Lin, R., Meri, S., Uzé, G., Hiscott, J., and Julkunen, I. 2006, J. Virol., 80, 3515.

[30] Davidson, S., Kaiko, G., Loh, Z., Lalwani, A., Zhang, V., Spann, K., Foo, S.Y., Hansbro, N., Uematsu, S., Akira, S., Matthaei, K.I., Rosenberg, H.F., Foster, P.S., and Phipps, S. 2011, J. Immunol., 186, 5938.

[31] Wang, J., Oberley-Deegan, R., Wang, S., Nikrad, M., Funk, C.J., Hartshorn, K.L., and Mason, R.J. 2009, J. Immunol., 182, 1296.

[32] Coccia, E.M., Severa, M., Giacomini, E., Monneron, D., Remoli, M.E., Julkunen, I., Cella, M., Lande, R., and Uzé, G. 2004, Eur. J. Immunol., 34, 796.

[33] Tissari, J., Sirén, J, Meri, S., Julkunen, I., and Matikainen, S. 2005, J. Immunol., 174, 4289.

[34] Kotenko, S.V., Krause, C.D., Izotova, L.S., Pollack, B.P., Wu, W., and Pestka, S. 1997, EMBO J., 16, 5894.

[35] Xie, M.H., Aggarwal, S., Ho, W.H., Foster, J., Zhang, Z., Stinson, J., Wood, W.I., Goddard, A.D., and Gurney, A.L. 2000, J. Biol. Chem., 275, 31335.

[36] Kotenko, S.V., Izotova, L.S., Mirochnitchenko, O.V., Esterova, E., Dickensheets, H., Donnelly, R.P., and Pestka, S. 2001, J. Biol. Chem., 276, 2725.

[37] Sheikh, F., Baurin, V.V., Lewis-Antes, A., Shah, N.K., Smirnov, S.V., Anantha, S., Dickensheets, H., Dumoutier, L., Renauld, J.C., Zdanov, A., Donnelly, R.P., and Kotenko, S.V. 2004, J. Immunol., 172, 2006.

[38] Langer, J.A., Cutrone, E.C., and Kotenko, S.V. 2004, Cytokine Growth Factor Rev., 15, 33. [39] Donnelly, R.P., Sheikh, F., Kotenko, S.V., and Dickensheets, H. 2004, J. Leukoc. Biol., 76, 314.

[40] Yoon, S.I., Logsdon, N.J., Sheikh, F., Donnelly, R.P., and Walter, M.R. 2006, J. Biol. Chem., 281, 35088.

[41] Wolk, K., and Sabat, R. 2006, Cytokine Growth Factor Rev., 17, 367.

[42] Gibbs, V.C., and Pennica, D. 1997, Gene, 186, 97.

[43] Sommereyns, C., Paul, S., Staeheli, P., and Michiels, T. 2008, PLoS Pathog., 4, e1000017.

[44] Brand, S., Beigel, F., Olszak, T., Zitzmann, K., Eichhorst, S.T., Otte, J.M., Diebold, J., Diepolder, H., Adler, B., Auernhammer, C.J., Göke, B., and Dambacher, J. 2005, Am. J. Physiol. Gastrointest. Liver Physiol., 289, G960.

[45] Meager, A., Visvalingam, K., Dilger, P., Bryan, D., and Wadhwa, M. 2005, Cytokine, 31, 109.

[46] Numasaki, M., Tagawa, M., Iwata, F., Suzuki, T., Nakamura, A., Okada, M., Iwakura, Y., Aiba, S., and Yamaya, M. 2007, J. Immunol., 178, 5086.

[47] Sato, A., Ohtsuki, M., Hata, M., Kobayashi, E., and Murakami, T. 2006, J. Immunol., 176, 7686.

[48] Siebler, J., Wirtz, S., Weigmann, B., Atreya, I., Schmitt, E., Kreft, A., Galle, P.R., and Neurath, M.F. 2007, Gastroenterology, 132, 358.

[49] Pestka, S., Krause, C.D., and Walter, M.R. 2004, Immunol. Rev., 202, 8.

[50] Walter, M.R. 2004, Adv. Protein Chem., 68, 171. 
[51] Brand, S., Zitzmann, K., Dambacher, J., Beigel, F., Olszak, T., Vlotides, G., Eichhorst, S.T., Göke, B., Diepolder, H., and Auernhammer, C.J. 2005, Biochem. Biophys. Res. Commun., 331, 543.

[52] Zitzmann, K., Brand, S., Baehs, S., Göke, B., Meinecke, J., Spöttl, G., Meyer, H., and Auernhammer, C.J. 2006, Biochem. Biophys. Res. Commun., 344, 1334.

[53] Pfeffer, L.M., Dinarello, C.A., Herberman, R.B., Williams, B.R., Borden, E.C., Bordens, R., Walter, M.R., Nagabhushan, T.L., Trotta, P.P., and Pestka, S. 1998, Cancer Res., 58, 2489.

[54] Bracci, L., Proietti, E., and Belardelli, F. 2007, Ann. N. Y. Acad. Sci., 1112, 256.

[55] Ferrantini, M., Capone, I., and Belardelli, F. 2007, Biochimie, 89, 884.

[56] Li, Q., Kawamura, K., Ma, G., Iwata, F., Numasaki, M., Suzuki, N., Shimada, H., and Tagawa, M. 2010, Eur. J. Cancer, 46, 180.

[57] Doyle, S.E., Schreckhise, H., Khuu-Duong, K., Henderson, K., Rosler, R., Storey, H., Yao, L., Liu, H., Barahmand-pour, F., Sivakumar, P., Chan, C., Birks, C., Foster, D., Clegg, C.H., Wietzke-Braun, P., Mihm, S., and Klucher, K.M. 2006, Hepatology, 44, 896.

[58] Marcello, T., Grakoui, A., Barba-Spaeth, G., Machlin, E.S., Kotenko, S.V., MacDonald, M.R., and Rice, C.M. 2006, Gastroenterology, 131, 1887.

[59] Guenterberg, K.D., Grignol, V.P., Raig, E.T., Zimmerer, J.M., Chen, A.N., Blaskovits, F.M., Young, G.S., Nuovo, G.J., Mundy, B.L., Lesinski, G.B., and Carson, W.E. 3rd. 2010, Mol. Cancer Ther., 9, 510.

[60] Fujie, H., Tanaka, T., Tagawa, M., Kaijun, N., Watanabe, M., Suzuki, T., Nakayama, K., and Numasaki, M. 2011, Cancer Sci., 102, 1977.

[61] Chin, Y.E., Kitagawa, M., Su, W.C., You, Z.H., Iwamoto, Y., and Fu, X.Y. 1996, Science, 272,719 .

[62] Sangfelt, O., Erickson, S., Einhorn, S., and Grandér, D. 1997, Oncogene, 14, 415.

[63] Sangfelt, O., Erickson, S., Castro, J., Heiden, T., Gustafsson, A., Einhorn, S., and Grandér, D. 1999, Oncogene, 18, 2798.

[64] Iwase, S., Furukawa, Y., Kikuchi, J., Nagai, M., Terui, Y., Nakamura, M., and Yamada, H. 1997, J. Biol. Chem., 272, 12406.

[65] Maher, S.G., Sheikh, F., Scarzello, A.J., Romero-Weaver, A.L., Baker, D.P., Donnelly, R.P., and Gamero A.M. 2008, Cancer Biol. Ther., 7, 1109.

[66] Li, W., Lewis-Antes, A., Huang, J., Balan, M., and Kotenko, S.V. 2008, Cell Prolif., 41, 960.

[67] Lesinski, G.B., Raig, E.T., Guenterberg, K., Brown, L., Go, M.R., Shah, N.N., Lewis, A., Quimper, M., Hade, E., Young, G., Chaudhury, A.R., Ladner, K.J., Guttridge, D.C., Bouchard, P., and Carson, W.E. 3rd. 2008, Cancer Res., 68, 8351.

[68] Fidler, I.J. 2000, J. Natl. Cancer Inst., 28, 10.

[69] Heyns, A.D., Eldor, A., Vlodavsky, I., Kaiser, N., Fridman, R., and Panet, A. 1985, Exp. Cell Res., 161, 297.

[70] Ruszczak, Z., Detmar, M., Imcke, E., and Orfanos, C.E. 1990, J. Invest. Dermatol., 95, 693.

[71] Hicks, C., Breit, S.N., and Penny, R. 1989, Cell Biol., 67, 271.

[72] Brouty-Boyé, D., and Zetter, B.R. 1980, Science, 208, 516.

[73] von Marschall, Z., Scholz, A., Cramer, T., Schäfer, G., Schirner, M., Oberg, K., Wiedenmann, B., Höcker, M., and Rosewicz, S. 2003, J. Natl. Cancer Inst., 95, 437.

[74] Dinney, C.P., Bielenberg, D.R., Perrotte, P., Reich, R., Eve, B.Y., Bucana, C.D., and Fidler, I.J. 1998, Cancer Res., 58, 808. 
[75] Singh, R.K., Gutman, M., Llansa, N., and Fidler, I.J. 1996, J. Interferon Cytokine Res., 16, 577.

[76] Fabra, A., Nakajima, M., Bucana, C.D., and Fidler, I.J. 1992, Differentiation, 52, 101.

[77] Ezekowitz, R.A., Mulliken, J.B., and Folkman, J. 1992, N. Engl. J. Med., 326, 1456.

[78] Real, F.X., Oettgen, H.F., and Krown, S.E. 1986, J. Clin. Oncol., 4, 544.

[79] Legha, S.S. 1997, Semin. Oncol., 24(1 Suppl 4), S39.

[80] Stadler, W.M., Kuzel, T.M., Raghavan, D., Levine, E., Vogelzang, N.J., Roth, B., and Dorr, F.A. 1997, Eur. J. Cancer, 33 Suppl 1, S23.

[81] Jordan, W.J., Eskdale, J., Boniotto, M., Rodia, M., Kellner, D., and Gallagher, G. 2007, Genes Immun., 8, 13.

[82] Pekarek, V., Srinivas, S., Eskdale, J., and Gallagher, G. 2007, Genes Immun., 8, 177.

[83] Tough, D.F., Borrow, P., and Sprent, J. 1996, Science, 272, 1947.

[84] Marrack, P., Kappler, J., and Mitchell, T. 1999, J. Exp. Med., 189, 521.

[85] Hung, K., Hayashi, R., Lafond-Walker, A., Lowenstein, C., Pardoll, D., and Levitsky, H. 1998, J. Exp. Med., 188, 2357.

[86] Segal, B.M., Glass, D.D., and Shevach, E.M. 2002, J. Immunol., 168, 1.

[87] Clarke, S.R. 2000, J. Leukoc. Biol., 67, 607.

[88] Lo, C.H., Lee, S.C., Wu, P.Y., Pan, W.Y., Su, J., Cheng, C.W., Roffler, S.R., Chiang, B.L., Lee, C.N., Wu, C.W., and Tao, M.H. 2003, J. Immunol., 171, 600.

[89] Martinotti, A., Stoppacciaro, A., Vagliani, M., Melani, C., Spreafico, F., Wysocka, M., Parmiani, G., Trinchieri, G., and Colombo, M.P. 1995, Eur. J. Immunol., $25,137$.

[90] Sutmuller, R.P., van Duivenvoorde, L.M., van Elsas, A., Schumacher, T.N., Wildenberg, M.E., Allison, J.P., Toes, R.E., Offringa, R., and Melief, C.J. 2001, J. Exp. Med., 194, 823.

[91] Mennechet, F.J., and Uzé, G. 2006, Blood, 107, 4417.

[92] Orange, J.S., and Biron, C.A. 1996, J. Immunol., 156, 4746.

[93] Biron, C.A., Nguyen, K.B., Pien, G.C., Cousens, L.P., and Salazar-Mather, T.P. 1999, Annu. Rev. Immunol., 17, 189.

[94] Kasaian, M.T., Whitters, M.J., Carter, L.L., Lowe, L.D., Jussif, J.M., Deng, B., Johnson, K.A., Witek, J.S., Senices, M., Konz, R.F., Wurster, A.L., Donaldson, D.D., Collins, M., Young, D.A., and Grusby, M.J. 2002, Immunity, 16, 559.

[95] Abushahba, W., Balan, M., Castaneda, I., Yuan, Y., Reuhl, K., Raveche, E., Torre, A.D.L., Lazfar, A., and Kotenko, S.V. 2010, Cancer Immnol. Immunother., 59, 1059.

[96] Stoppacciaro, A., Melani, C., Parenza, M., Mastracchio, A., Bassi, C., Baroni, C., Parmiani, G., and Colombo, M.P. 1993, J. Exp. Med., 178, 151.

[97] Boehm, U., Klamp, T., Groot, M., and Howard, J.C. 1997, Annu. Rev. Immunol., 15, 749.

[98] Dighe, A.S., Richards, E., Old, L.J., and Schreiber, R.D. 1994, Immunity, 1, 447.

[99] Angiolillo, A.L., Sgadari, C., Taub, D.D., Liao, F., Farber, J.M., Maheshwari, S., Kleinman, H.K., Reaman, G.H., and Tosato, G. 1995, J. Exp. Med., 182, 155.

[100] Addison, C.L., Arenberg, D.A., Morris, S.B., Xue, Y.Y., Burdick, M.D., Mulligan, M.S., Iannettoni, M.D., and Strieter, R.M. 2000, Gene Ther., 11, 247.

[101] Cousens, L.P., Orange, J.S., Su, H.C, and Biron, C.A. 1997, Proc. Natl. Acad. Sci. U S A., 94, 634 .

[102] McRae, B.L., Semnani, R.T., Hayes, M.P., and van Seventer, G.A. 1998, J. Immunol., $160,4298$.

[103] Liu, B.-S., Janssen, H.L.A., and Boonstra, A. 2010, Blood, 117, 2385. 
[104] Sareneva, T., Matikainen, S., Kurimoto, M., and Julkunen, I. 1998, J. Immunol., 160, 6032.

[105] Wenner, C.A., Güler, M.L., Macatonia, S.E., O'Garra, A., and Murphy, K.M. 1996, J. Immunol., 156, 1442.

[106] Mu, J., Zou, J.P., Yamamoto, N., Tsutsui, T., Tai, X.G., Kobayashi, M., Herrmann, S., Fujiwara, H., and Hamaoka, T. 1995, Cancer Res., 55, 4404.

[107] Gri, G., Chiodoni, C., Gallo, E., Stoppacciaro, A., Liew, F.Y., and Colombo, M.P. 2002, Cancer Res., 62, 4390.

[108] Zilocchi, C., Stoppacciaro, A., Chiodoni, C., Parenza, M., Terrazzini, N., and Colombo, M.P. 1998, J. Exp. Med., 188, 133.

[109] Rogge, L., Barberis-Maino, L., Biffi, M., Passini, N., Presky, D.H., Gubler, U., and Sinigaglia, F. 1997, J. Exp. Med., 185, 825.

[110] Rogge, L., D'Ambrosio, D., Biffi, M., Penna, G., Minetti, L.J., Presky, D.H., Adorini, L., and Sinigaglia, F. 1998, J. Immunol., 161, 6567.

[111] Ank, N., Iversen, M.B., Bartholdy, C., Staeheli, P., Hartmann, R., Jensen, U.B., DagnaesHansen, F., Thomsen, A.R., Chen, Z., Haugen, H., Klucher, K., and Paludan, S.R. 2008, J. Immunol., 180, 2474. 


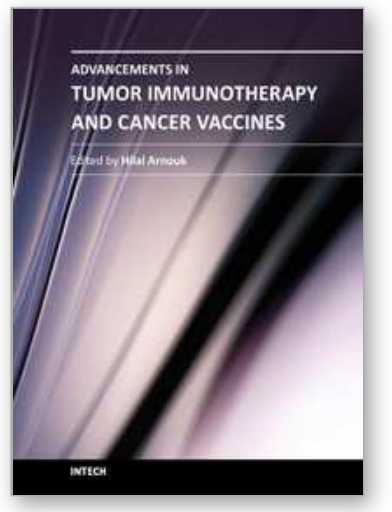

\author{
Advancements in Tumor Immunotherapy and Cancer Vaccines \\ Edited by Dr. Hilal Arnouk
}

ISBN 978-953-307-998-1

Hard cover, 218 pages

Publisher InTech

Published online 03, February, 2012

Published in print edition February, 2012

Harnessing the potential of the human body's own immune system to attack malignant tumor cells has been the goal of many scientific investigators in recent years, with advances in cancer biology and immunology enabling cancer immunotherapy to become a reality. World-class bench and clinical researchers have joined forces to collaborate and review current developments and trends in cancer immunology for the purposes of this book, and the result is a promising review of contemporary clinical treatments. In each chapter the authors present the scientific basis behind such therapeutic approaches, including cancer vaccines with special focus on prostate cancer, melanoma and novel approaches utilizing both innate and adaptive immune responses.

\title{
How to reference
}

In order to correctly reference this scholarly work, feel free to copy and paste the following:

Hitomi Fujie and Muneo Numasaki (2012). Type III Interferons IL-28 and IL-29: Novel Interferon Family Members with Therapeutic Potential in Cancer Therapy, Advancements in Tumor Immunotherapy and Cancer Vaccines, Dr. Hilal Arnouk (Ed.), ISBN: 978-953-307-998-1, InTech, Available from:

http://www.intechopen.com/books/advancements-in-tumor-immunotherapy-and-cancer-vaccines/type-iii-ifns-il28-and-il-29-novel-interferon-family-members-with-therapeutic-potential-in-cancer-t

\section{INTECH}

open science | open minds

\section{InTech Europe}

University Campus STeP Ri

Slavka Krautzeka 83/A

51000 Rijeka, Croatia

Phone: +385 (51) 770447

Fax: +385 (51) 686166

www.intechopen.com

\section{InTech China}

Unit 405, Office Block, Hotel Equatorial Shanghai

No.65, Yan An Road (West), Shanghai, 200040, China

中国上海市延安西路65号上海国际贵都大饭店办公楼 405 单元

Phone: +86-21-62489820

Fax: +86-21-62489821 
(C) 2012 The Author(s). Licensee IntechOpen. This is an open access article distributed under the terms of the Creative Commons Attribution 3.0 License, which permits unrestricted use, distribution, and reproduction in any medium, provided the original work is properly cited. 